\title{
Design and Implementation of an Online Auction in Al-Somhan Showroom with Information Technology and Information System Strategy
}

\author{
Hilal Hamed AL-Baddaei ${ }^{1}$ and Mohammad Saqibi" \\ ${ }^{1}$ Centre for Postgraduate Studies, Middle East College, Muscat, Sultanate of Oman \\ \#Advisor
}

\section{$\underline{\text { ABSTRACT }}$}

E-commerce is one of the best current trade because it contains many advantages and ease of traditional trade, especially at the time of the current pandemic. Therefore, most governmental and private institutions are trying to electronic transformation as soon as possible to stay on the commercial scene. Among these institutions is the Al Somhan Used Cars Exhibition. Therefore, this research paper will discuss the process of design and implementation of an online auction site for the Al Somahan Used Cars Exhibition. First, there will be a study and strategies on the transition from the traditional auction to the electronic auction, and what are the strategies for the technology that will be used in this transformation. Some comparisons will be made between online auctions such as eBay, Amazon, Copart ... and others. The paper will also contain some advantages and disadvantages in the online auction, the most important of which are security and fraud. The website design method will also be explained using the Visual Studio program. Also, the researcher will insert some diagrams, such as the use case diagram, class diagram, ERD...etc. Now a day people like to use their mobile phone too much so the mobile phone application will be design and implement to make life easy for the customers.

\section{Introduction}

In recent years, car showrooms have increased in the region due to the prohibition of random display of cars in public streets and parking lots by the Royal Oman Police. Therefore, merchants sought to open special shops to display used cars, which would enable them to display cars to them and customers without any violations. Exhibitions are the Al Somhan used car fair Since its establishment, it displays cars to customers in front of the exhibition square. Therefore, the buyer must either visit the exhibition in person or communicate with one of the officials in the exhibition. Or visit their official pages on social media sites. The exhibition management is always looking for an increase in the number of customers and beneficiaries of the exhibition services (Rehman, Uddin, Khan and Zeb, 2019). Therefore, the administration headed by Mr. Samir Jalal Al Balushi decided to establish a website to manage the display of cars and hold periodic auctions on it, which will achieve the increase in the number of customers at the exhibition. This transformation will require designing an online auction website for this exhibition and how the IT/IS strategy will implement it. (Alqam, H. and Nair, S., 2018)

With the increase in these exhibitions, there is great competition in this area to develop the buying and selling process. Some exhibitions tended to sell through the online auction, (Shi, Zhang, Wu, Li \& Lau, 2016) but unfortunately, there is no special platform for selling through auction, but they used social media programs such as Instagram by making a live broadcast. Therefore, creating a special platform for the exhibition will be a great opportunity to increase the sale and purchase of the exhibition. This platform will facilitate many matters related to the sale and purchase of cars. 


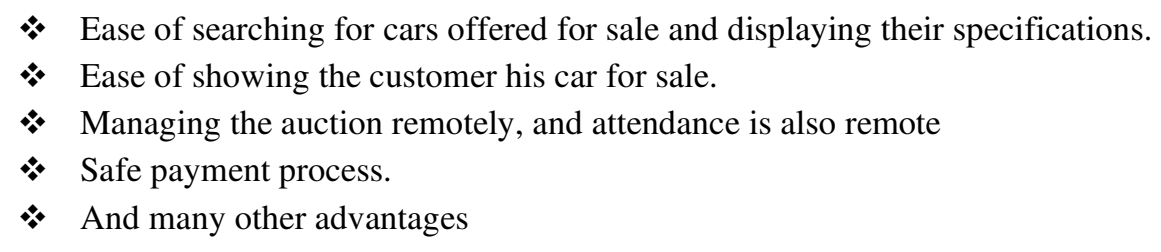

In the beginning, the exhibition manager must prepare for a fundamental change in the management of the exhibition from traditional management to technical management. A robust and strategic technical plan will be implemented to enable the technical management of the exhibition. The transformation or the work of an information technology project needs a comprehensive study of the benefits, advantages, and disadvantages of this implementation. Through SWOT (Takamatsu et al., 2016) and PESTEL analysis, the things that will be presented by this transformation will be discussed.

E-commerce has made a big difference in the curve of financial trading with major international companies. This made it easier for customers and users to conduct their transactions remotely and comfortably. Therefore, major companies deliberately entered auction sales of their products to attract the largest number of customers. Large websites such as eBay, Amazon, and Copart have spared very large profits by implementing them for online auctions. The number of users has increased significantly, and profits have increased significantly in a few years. All this indicates that the customers like to be managing their business and buying them easy and simple. The figure below shows how much those companies sell in the last 3 years.

\begin{tabular}{lrrr} 
& $\mathbf{2 0 1 7}$ & $\mathbf{2 0 1 8}$ & $\mathbf{2 0 1 9}$ \\
Amazon & $42.0 \%$ & $44.8 \%$ & $47.0 \%$ \\
\hline eBay & $7.6 \%$ & $6.8 \%$ & $6.1 \%$ \\
\hline Walmart & $3.3 \%$ & $4.0 \%$ & $4.6 \%$ \\
\hline Apple & $3.8 \%$ & $3.8 \%$ & $3.8 \%$ \\
\hline The Home Depot & $1.4 \%$ & $1.6 \%$ & $1.7 \%$ \\
\hline
\end{tabular}

Figure1. Online Auction Selling Percentages.

\section{Related Work and Problem Motivation}

In this part, the researcher will describe some of the existing online auction systems that are used now and the motivation for designing and implementing Al-Somhan online auction.

\section{Existing Online Auction System.}

eBay is one of the first websites that appeared in preparing auctions on its pages (McCarthy, 2018). It started in 1995 and since that day, they have been developing this system. Most of the electronic systems specialized in the auction are considered to provide the same bid and buy services, but they are distinguished in the methods of bidding. And also all sites or online auction systems fight fraudulent methods in bidders such as shilling bid and bid shield, which will be explained later (Majadi, Trevathan \& Bergmann, 2016). This site is distinguished by the types of bidding that the customer can use ("How Does Bidding On Ebay Work The Best Guides Selected| Addhowto", 2021), such as automatic bidding, a reversal of an auction if the bidder erred in listing a certain value and returning the 
opportunity to buyers who were not fortunate to win the auction, as well as equality between the bidders is present for everyone and there is no preference for the existing customers over the two new ones

eCrater is one of the easiest auction websites. The merchandise offered is of good quality and is mostly sourced from eBay and Amazon. As for customers, it is considered that the rare sites that sell without forcing the customer to register on the site ("Effects of Billboards on Buying Behavior of Customer in Context of Textile Products", 2019). All that the user has to choose the product, add it to the basket and follow the steps to the end of the purchase. Bidding on this website is very easy. And they develop more features. Also, they have a mobile application which is works at the same time as the website.

As customers and the general customers, we are faced with a problem with the electronic auction sites without knowing how to deal with the sellers. This is what distinguishes the e-auction site, which is that it is the seller and the buyer, among whom the processes are direct. In particular, ("Save Time and Improve your Marks with CiteThisForMe, The No. 1 Citation Tool", 2021) the seller deals with the factory himself. That is, the user is bidding for goods while they are in the factory. That is, there is no third party or intermediary between the customer and the goods (soojin jung \& 위지윤, 2014). Even the selection on this website is more limited than others but it a good place where the customers are looking for items like watches, coins, or electronics. Also, the fast auction is available in this online auction which lasts for 20 minutes for the customer who pays more. (Essaili, Schroeder, Steinbach, Staehle \& Shehada, 2015).

Also, there are different sites and systems, and each has different features, including the method of payment, purchase, and shipping. And several advantages that differ from system to system, including the quality of payment, fast charging, and the introduction of new technologies such as machine learning. (Weissteiner \& Seuken, 2020).

\section{Problem Motivation}

Given previous experiences and analysis of some previous literature regarding online auctions, the researcher conducted a study on how to design this system to avoid general problems and develop our system to simulate the existing auctions. Among the objectives of this paper is to design an excellent and practical system that contains what customers need in our region. Some reason which makes the exhibition to implement this system are:

- Using technology to facilitate the buying and selling of cars

- Increasing the number of exhibition customers by facilitating display

- Court management of the exhibition and its exhibits

- System development to reasonable limits

\section{It/Is Strategy}

Al Somhan Used Cars Showroom does not have many Techniques of modern technology. Therefore, to design and implement this system for it, we need a specific strategy to apply technology in it. An information technology strategy IT/IS (2021). a comprehensive study and plan for the project that defines the method of using technology to meet the goals of this system. To prepare it, certain conditions are written and clear in detail and study all aspects that will affect the project. Project cost management, human capital management, equipment used in the project, and many aspects must be clear before establishing the system to make a comprehensive project efficiency and success. Usually, they are two types of analysis techniques that use to analyze the need of the project. SWOT and PESTEL analysis. The next table will explain those analyses.

\section{A. SWOT Analysis}


There are always strengths and weaknesses about any project that is intended to succeed, and also there are opportunities and threats that hinder the success of the project. Therefore, in this system, we analyzed these points using SWOT Analysis, (Chen \& Kodono, 2014) which is a summary of the Strength of Weakness, Opportunities, and Threat. The next table is describing SWOT analysis for this system. ("Swot Analysis Of Aalsmeer Flower Auctions Information Technology Essay", 2021).

Table 1. SWOT analysis of Al Somhan online auction

\begin{tabular}{|c|c|c|c|}
\hline$S$ & W & $\mathrm{O}$ & $\mathrm{T}$ \\
\hline $\begin{array}{l}\text { Quick ser- } \\
\text { vice } \\
24 / 7 \text { service } \\
\text { Financing } \\
\text { procedures } \\
\text { from all lo- } \\
\text { cal finance } \\
\text { companies }\end{array}$ & $\begin{array}{l}\text { Budget limi- } \\
\text { tation } \\
\text { Small space } \\
\text { less skill in } \\
\text { IT }\end{array}$ & $\begin{array}{l}\text { Distin- } \\
\text { guished } \\
\text { location } \\
\text { Bring in } \\
\text { wealthy } \\
\text { clients } \\
\text { Advertise- } \\
\text { ments by } \\
\text { famous so- } \\
\text { cial Media } \\
\text { people } \\
\text { Motiva- } \\
\text { tional con- } \\
\text { tests }\end{array}$ & $\begin{array}{l}\text { Increase the } \\
\text { number of exhi- } \\
\text { bition } \\
\text { Banning the sale } \\
\text { of new cars at the } \\
\text { exhibition } \\
\text { Extra fees for } \\
\text { customers }\end{array}$ \\
\hline
\end{tabular}

\section{B. PESTEL Analysis}

During the implementation of any project or even before the start of implementation, there are external factors that may cause and affect the success of the project. Therefore, project management must study these factors and carry out an analysis. These factors are, for example, political, economic, social, technological, environmental, and legal factors. In our system, the researcher will study these factors and analyze them to deal with these factors and take into account their causes while doing this research. This analysis is called a PESTEL analysis ("Oxford College of Marketing Blog - Your Training and Development Partner", 2021). To ensure all work is in good condition this analysis must be done per month or 3 months. Most of the organizations are monitoring and responding to this analysis to be ready for any changes that may happen. The next table will analysis PESTEL for this system.

Table2. PESTEL analysis of Al Somhan Auction

\begin{tabular}{|l|l|}
\hline P & ----------------------------- \\
\hline E & $\begin{array}{l}\text { Municipal laws and taxes } \\
\text { Affected global cropping } \\
\text { New laws from the Royal Oman Police }\end{array}$ \\
\hline S & $\begin{array}{l}\text { The community accepts the idea of an electronic auc- } \\
\text { tion } \\
\text { Society's fear of fraud and electronic extortion } \\
\text { Habits and norms }\end{array}$ \\
\hline
\end{tabular}




\begin{tabular}{|l|l|}
\hline $\mathrm{T}$ & $\begin{array}{l}\text { Internet availability in all parts of Oman } \\
\text { Internet speed } \\
\text { Knowledge and culture of users on electronic payment }\end{array}$ \\
\hline $\mathrm{E}$ & $\begin{array}{l}\text { Combination in finance and insurance } \\
\text { A system approved by the Ministry of Technology and } \\
\text { Communications } \\
\text { A secure payment system by Digital Oman }\end{array}$ \\
\hline $\mathrm{L}$ & $\begin{array}{l}\text { Prepare for any fire } \\
\text { Weather damage to the cars shown }\end{array}$ \\
\hline
\end{tabular}

\section{Research Methodology}

To create a system and design, it must be carefully studied. Therefore, most of these systems were designed using a rigorous research methodology. To implement the systems, there are several methodologies such as Waterfall, Spiral, Iterative Model, Agile, and SCRUM.

\section{A. SCRUM}

In this system, we will use SCRUM methods to get the best possible result. Many advantages compelled us to use this methodology, including continuous and collective work. Especially sprints, which help to improve the system during work and design. An example of this is if we have finished the design process and moved to another part and there are notes regarding the design, then returning the sprint every month helps to modify things and obtain a distinctive result. The following table will show what works we have carried out in this system.

Table3. SCRUM Sprints

\begin{tabular}{|l|l|}
\hline Sprint 1 & Organize the items \\
\cline { 2 - 2 } & Fast in use \\
\cline { 2 - 2 } & List item specification \\
\hline Sprint 2 & User Profile \\
\cline { 2 - 2 } & An easy and fast bidding \\
\cline { 2 - 2 } & The search feature in the system \\
\hline Sprint 3 & Payment method \\
\cline { 2 - 2 } & Admin permeation \\
\cline { 2 - 2 } & User registration \\
\cline { 2 - 2 } & Notification \\
\hline
\end{tabular}

\section{Design AL SOMHAN System}

To design the system, we will use some of the charts that will help us to get a good system. A flow chart is one of these charts which will help us to know how the process will move from step to the next step. The next figure will show the flow of the process since the user visits the website to the end of his payment. 


\section{A. Flow Chart}

A flowchart is a graphical representation that illustrates the steps that summarize the functioning of the system (2021). It displays these steps sequentially to illustrate the processes that will take place in the system. It also works to explain the algorithms in a typical manner and differentiates the type of operations through the different shapes and arrows.

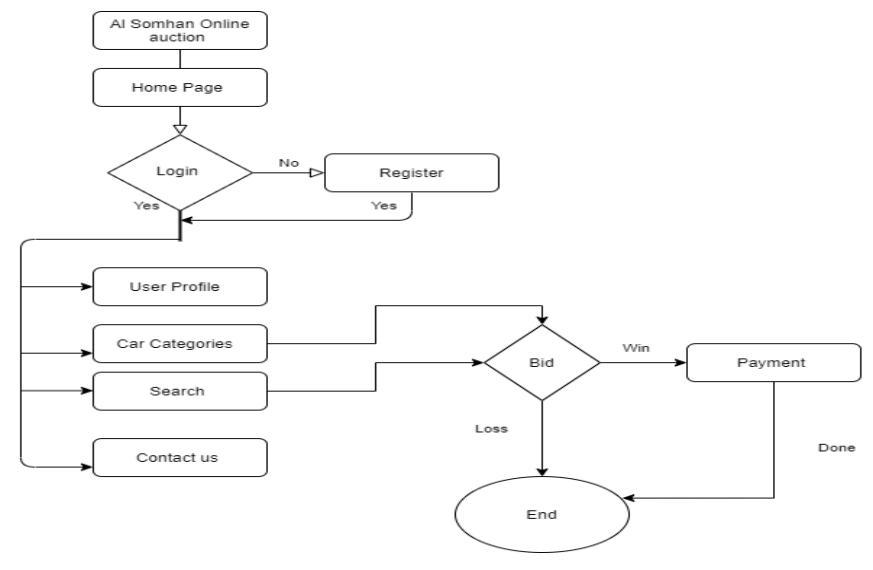

Figure 2. Al Somhan System Flow Chart

If the user likes to use this online auction he has first to open the browser and type the page address. The home page and general information about the exhibition will appear for him. If the user wants to see the exhibits and participate in auctions, he must first register and then log in. If wants to bid $\mathrm{n}$ any car, he must search for a car that will be auctioned in, and if he wins it, he proceeds to the payment process and thus the auction process ends.

\section{B. Use case diagram}

The use case diagram is an illustration of what operations people perform. It clarifies the limits of the user's use of the system; what he can do and what is withheld from him. It also shows the possibility and comprehensiveness of the admin on all pages on the site (Vachharajani \& Pareek, 2014). The following figure will show the diagram which will explain the system operations.

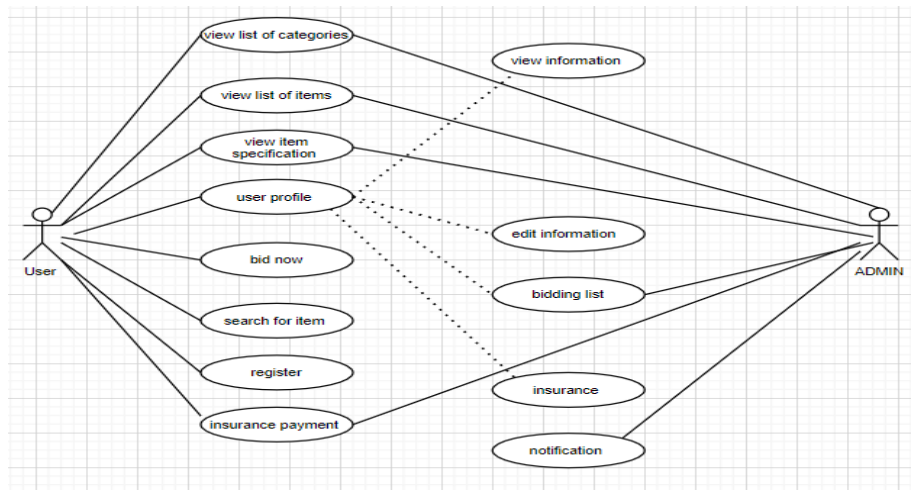

Figure 3. Al Somhan System Use Case Diagram 
The above figure showed that the user has limited and simple browsing capabilities, unlike an admin, he has a comprehensive ability to see most of the user's process from private information, record history, bids, and so on.

\section{Class Diagram}

To build any system you have to use a class diagram which is the main object-oriented modeling. It represents the main structure of the system process. And the coding is building from this diagram. The next figure will show the class diagram of the Al Somahn showroom system.

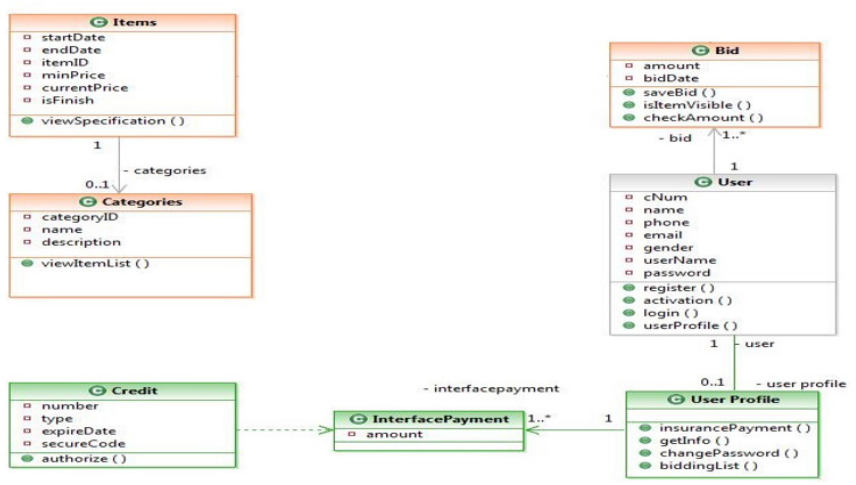

Figure 4. Al Somhan System Class Diagram.

\section{Implement AL SOMHAN System}

After completing the basic design of the system. Now it remains to use the Visual Studio program to implement the system. In this program, the basic codes have been written to run the system. Every window on the website has a spacing code and each has a type, font, and color of the words. The following figure shows the work we have done to write the codes.

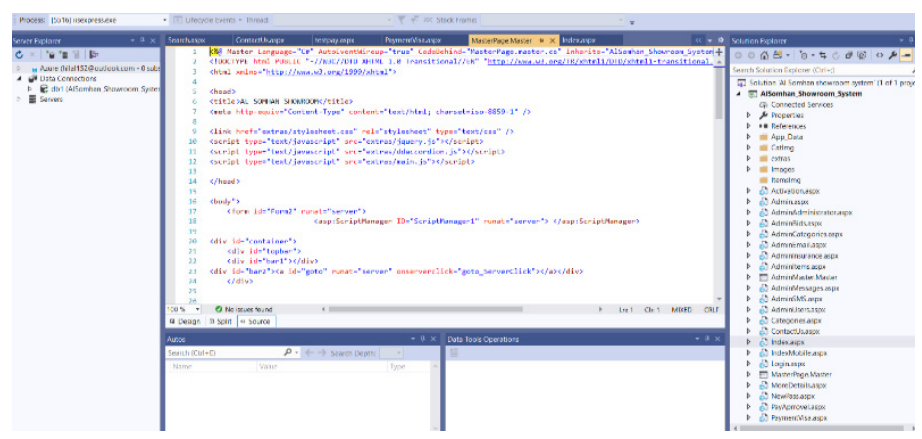

Figure 5. Visual Studio. Al Somhan System Codes

So after writing all codes in proper ways you can test the system if it is work or not by clicking on the play to look on the demo. The figure below will shows the home page of the Al Somhan system. 


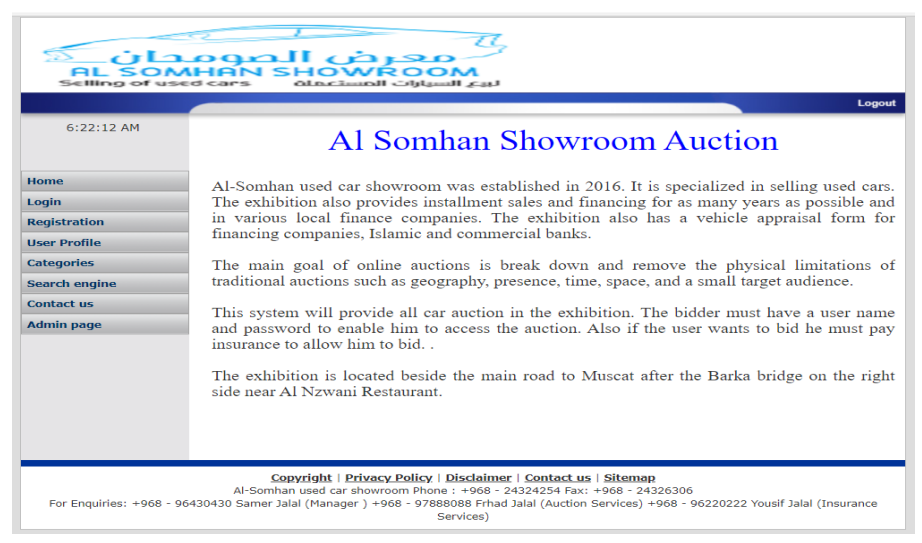

Figure 6. Al Somhan System Home Page

So this is our website which we were talking about. It is now ready to use and easy to access. The user now can register and select what he inters on and view the cars and bid if he has done everything.

\section{Conclusion}

This is the system that we implemented at the request of the Al Sohan Used Cars Showroom. A system in which there will be great benefit from achieving technology and benefiting from it. Likewise, we do not forget that these days, due to the Coronavirus, there is distancing and preventing gatherings, and this often happens in the auction yards. Therefore, this system will make it easier for everyone to buy and sell. This system is designed professionally and using all scientific and international strategies and methodologies in creating projects. Also, in designs, we used basic diagrams and charts to create any system or websites. Finally, we hope this system will see the light soon on international browsers.

\section{Future Work}

This system is considered a beginner system to see if there are encouragement and admiration from customers and users. For this, many things can be developed, such as setting up a phone application that links to the site to make it easier for customers. Also, on the issue of the tambourine, safety is always and badly required by everyone. Especially, we aspire to make the auction be $100 \%$ without human intervention for the sake of availability all the time.

\section{References}

Rehman, J., Uddin, J., Khan, A. and Zeb, A., 2019. A Cloud based CRM Architecture for Neural Network Inventory Control. 2019 International Conference on Electrical, Communication, and Computer Engineering (ICECCE), Alqam, H. and Nair, S., 2018. IS/IT Strategy Framework for Research Centers at Sultan Qaboos University: A Case Study in the Middle East. 2018 8th International Conference on Computer Science and Information Technology (CSIT),

Shi, W., Zhang, L., Wu, C., Li, Z., \& Lau, F. (2016). An Online Auction Framework for Dynamic Resource Provisioning in Cloud Computing. IEEE/ACM Transactions On Networking, 24(4), 2060-2073. doi:

10.1109/tnet.2015.2444657 
Takamatsu, K., Kirimura, T., Bannaka, K., Noda, I., Mitsunari, K., \& Omori, M. et al. (2016). SWOT Analysis and Complex Network Analysis to Enhance Governance in Universities by Collaboration between Academic and Administrative Faculty. 2016 5Th IIAI International Congress On Advanced Applied Informatics (IIAI-AAI). doi: 10.1109/iiai-aai.2016.207

McCarthy, L. (2018). Should State and Local Government Bidding for Big Businesses Be More Like eBay?. Growth And Change, 49(3), 400-412. doi: 10.1111/grow.12238

Majadi, N., Trevathan, J., \& Bergmann, N. (2016). Analysis on Bidding Behaviours for Detecting Shill Bidders in Online Auctions. 2016 IEEE International Conference On Computer And Information Technology (CIT). doi: 10.1109/cit.2016.48

How Does Bidding On Ebay Work The Best Guides Selected| Addhowto. (2021). Retrieved 19 April 2021, from https://www.addhowto.com/how-does-bidding-on-ebay-work

Save Time and Improve your Marks with CiteThisForMe, The No. 1 Citation Tool. (2021). Retrieved 19 April 2021, from https://www.citethisforme.com/topic-ideas/life-sciences/Writing\%20Week\%202-109638455

soojin jung, \& . (2014). UBID(University Brand Identity Design) Strategies for the Enhancement of International Status -Focusing on the Symbol Mark-. Journal Of Korea Design Knowledge, null(32), 129-140. doi:

$10.17246 / j k d k .2014 . .32 .013$

Effects of Billboards on Buying Behavior of Customer in Context of Textile Products. (2019). Journal Of Economics And Sustainable Development. doi: 10.7176/jesd/10-10-06

Essaili, A., Schroeder, D., Steinbach, E., Staehle, D., \& Shehada, M. (2015). QoE-Based Traffic and Resource Management for Adaptive HTTP Video Delivery in LTE. IEEE Transactions On Circuits And Systems For Video Technology, 25(6), 988-1001. doi: 10.1109/tcsvt.2014.2367355

Weissteiner, J., \& Seuken, S. (2020). Deep Learning_Powered Iterative Combinatorial Auctions. Proceedings Of The AAAI Conference On Artificial Intelligence, 34(02), 2284-2293. doi: 10.1609/aaai.v34i02.5606

(2021). Retrieved 20 April 2021, from https://searchcio.techtarget.com/definition/IT-strategy-information-technology-strategy.

Chen, F., \& Kodono, Y. (2014). Fuzzy VRIO and SWOT Analysis of Chery Automobile. Journal Of Advanced Computational Intelligence And Intelligent Informatics, 18(3), 429-434. doi: 10.20965/jaciii.2014.p0429

Swot Analysis Of Aalsmeer Flower Auctions Information Technology Essay. (2021). Retrieved 20 April 2021, from https://www.ukessays.com/essays/information-technology/swot-analysis-of-aalsmeer-flower-auctions-informationtechnology-essay.php

Oxford College of Marketing Blog - Your Training and Development Partner. (2021). Retrieved 20 April 2021, from https://blog.oxfordcollegeofmarketing.com/ (2021). Retrieved 20 April 2021, from https://re-

sources.sei.cmu.edu/asset_files/Presentation/2001_017_001_23277.pdf

Vachharajani, V., \& Pareek, J. (2014). A proposed Architecture for Automated Assessment of Use Case Diagrams. International Journal of Computer Applications, 108(4), 35-40. doi: 10.2150/18902-0193 